\title{
Comparison of Effectiveness of Radiation Therapy, Local Steroid Injection, and Extracorporeal Shock Wave Therapy in Patients with Plantar Fasciitis: A Multicenter Study
}

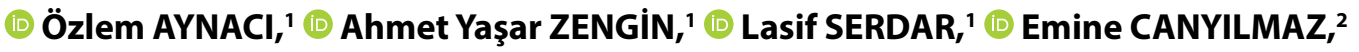 \\ (1) Fatih CANYILMAZ, 3 (1) Emel HACIISLAMOĞLU, ${ }^{2}$ (1) Fatma ZENGIN, 4 (D) Osman AYNACI, \\ (1) Adnan YÖNEY² \\ 'Department of Radiation Oncology, Kanuni Training and Research Hospital, Trabzon-Turkey \\ ${ }^{2}$ Department of Radiation Oncology, Karadeniz Technical University Faculty of Medicine, Trabzon-Turkey \\ ${ }^{3}$ Department of Orthopaedics and Traumatology, Yavuz Selim Bone Disease Hospital, Trabzon-Turkey \\ ${ }^{4}$ Department of Physical Therapy and Rehabilition, Fizyotem Special Center, Trabzon-Turkey \\ ${ }^{5}$ Department of Orthopaedics and Traumatology, Karadeniz Technical University Faculty of Medicine, Trabzon-Turkey
}

\begin{abstract}
OBJECTIVE
The aim of this study is, therefore, to compare three different treatment modalities for symptomatic plantar fasciitis (PF), namely, effective in pain control.

\section{METHODS}

This study involved 205 patients with a diagnosis of painful PFs, treated during the years 2013 through 2017 at three institutions. Of these, 67 patients received a total dose of 6.0 Gy radiotherapy (RT in 3-weekly fractions of $1 \mathrm{~Gy}$ (RT arm); 65 patients received local steroid injection (SI) of $40 \mathrm{mg}(1 \mathrm{ml})$ of methylprednisolone; and $0.5 \mathrm{ml}$ of $1 \%$ lidocaine in the painful heel spur, using palpation (palpation guided) (PG SI arm) and 73 received extracorporeal shock wave therapy (ESWT) in five sessions with weekly intervals (ESWT arm). Patients recorded visual analog scale (VAS) score, a modified Pannewitz score and a 5-level function score. Patients with available $\geq 12$ months of data were included in the present study.
\end{abstract}

\section{RESULTS}

Follow-up data were available for patients with a median of 15.5 (range, 6.5-37.4) months. There was a significant improvement in VAS scores and 5-level function scores in the RT arm at 3 and 6 month period arm $(\mathrm{p}<0.001)$. In univariate and multivariate analyses, only treatment scheme was associated with considerable pain control $(\mathrm{p}=0.006)$.

\section{CONCLUSION}

These findings suggest that all treatment modalities provide significant pain relief in patients with painful heel spur. This analysis also demonstrates RT is superior choice for chronic PF in cases of failure with conservative treatments when compared to extracorporeal shock wave therapy and PG SI.

Keywords: Awareness; educational level; electronic survey; knowledge; oral cancer; public health.

Copyright $\odot$ 2021, Turkish Society for Radiation Oncology 


\section{Introduction}

Plantar fasciitis (PF) (also called calcaneodynia, calcaneal periostitis or enthesopathy, PF) is the heel pain caused by degenerative irritation at the insertion of the plantar fascia on the medial process of the calcaneal tuberosity.[1] Micro rupture theory is one of the predicted pathological mechanisms for PF. According to this theory, micro tears occur over time in the PF due to the repetitive tensile forces of the PF after weight bearing; individuals who are predisposed develop chronic inflammatory fasciitis as a result, which is characterized by insufficient healing tissue in these micro-tears.[2] Typical symptoms include severe pain in the morning or after a resting period which improves with movement.[3]

There are two main approaches to treatment of PF: Conservative and surgical. In general, treatment plans initiate with patient-directed methods consisting of resting, activity modification, ice massage, and management programs with stretching and strengthening of the plantar fascia.[4] However, chronic symptoms may require more intensive conservative treatments such as nonsteroidal anti-inflammatory drugs, steroid injection (SI), night splints, orthotic devices, extracorporeal shock-wave therapy (ESWT), and iontophoresis.[5-9] There is an important and common consensus that about $70-90 \%$ of patients with PF find sufficient relief from non-surgical techniques.[10] Cases that do not respond to conservative treatment, first-line treatment including a SI, and that complain of the lengthy, stubborn, and severe PF for more than 6 months should be considered for surgical interventions like plantar fasciotomy.[11]

Historically radiotherapy (RT) has been used for the treatment of a wide range of benign tumors regardless of limited knowledge about its mechanisms of action in clinical practice. High dose RT induces production of pro-inflammatory cytokines, leading to an inflammatory response in the irradiated tissues. Contradictorily, $\mathrm{RT}$ administered at low doses (LD-RT) modulates the inflammatory response, producing several anti-inflammatory mechanisms such as impaired leukocyte adhesion, apoptosis in endothelial cells, and modulation of E- selectin adhesion on endothelial cells. Recent data have demonstrated that irradiation acts not through a single mechanism but through a complex interaction of different effects.[12-14] For decades, RT has been successfully applied in the treatment of PF although an optimal radiotherapy regimen remains unclear and under discussion.[15]
ESWT is a noninvasive procedure that is defined as the application of high density pressure waves to the body used for the first time to treat urolithiasis in 19701980.[16] ESWT promotes angiogenesis, increases perfusion in ischemic tissues, decreases inflammation, enhances cell differentiation, and accelerates wound healing to aid in healing degenerative tissue.[17] Many studies have shown that ESWT has positive effects, including pain reduction, although some studies have shown no positive effect. $[18,19]$ ESWT has been widely used as an alternative treatment due to other ineffective conservative procedures lasting for at least 6 months in the treatment of PF.

One method of among PF treatment is local SI, antiinflammatory medicines commonly used in the treatment of acute and chronic PF with proven effectiveness. SI can trigger the process of pain relief through its strong anti-inflammatory effect.[20] For cases which do not respond to other conservative therapies, a long-acting local anesthetic mixture with steroids is commonly used with ultrasonography-guided (UG), palpation-guided (PG), or scintigraphy-guided techniques to the region where pain is most severe.

Although the listed alternative methods all provide improvement in terms of pain relief, it is not clear which one is most effective. While there are several comparisons of SI and ESWT in the existing literature, there is no study comparing RT with ESWT. Hence, the aim of the present study was to retrospectively compare the therapeutic effects of three different treatment modalities (PG SI, RT, and ESWT) based on pain reduction.

\section{Materials and Methods}

This retrospective study included 205 patients who presented with PF and underwent RT, ESWT, and PG SI during the period of June 2013 to December 2017 at three institutions. To obtain information about the responses of patients treated with $\mathrm{PF}$, telephone interviews and e-mail survey methods were used. Our study sample was created by combining new patients and patients from the study conducted by Canyilmaz et al.[21] and by including new patients as the third arm of the ESWT group. The diagnosis of PF was established through a consistent method of history, physical exam, and radiographs by a single orthopedist. PF was confirmed clinically and radiologically in all patients with a proven heel spur and met all these criteria: Karnofsky performance status $\geq 70$, all patients had received various treatments previously and presented with symptoms such as pain and/or mobility restric- 
tions. Exclusion criteria were trauma to the foot, severe psychiatric disorders, rheumatic and/or vascular diseases, and pregnancy or breastfeeding.

The trial was submitted to the Research Ethics Committee at the Faculty of Medicine in Karadeniz Technical University where RT data were collected, for approval (2019/110). The study was conducted in accordance with the principles of the Declaration of Helsinki.

\section{Treatment}

RT was performed with a linear accelerator producing $6 \mathrm{MV}$ photons, applying lateral parallel opposing areas. Treatment portals were simulated in a supine position and included the whole calcaneus, insertion into the Achilles tendon, and plantar fascia insertion with appropriate fall off (Fig. 1). RT was given 3 times weekly in a single portal and six fractions of $1 \mathrm{~Gy}$ up to a total dose of 6 Gy. The radiation therapy sessions were performed on Monday, Wednesday, and Friday to avoid radiation therapy on consecutive days.

A Swiss Dolor Clast brand device was used to administer treatment for the ESWT with the patients in a prone position, 2000 (11 times per sec) shockwave impulses $(20 \mathrm{MHz})$ at 3 bar air pressure were delivered using a 16-mm head. After determining the regions of heel pain through physical examinations, gel was used between the cap and skin during the applications to ensure conductivity, and the shockwave energy was delivered by single physical therapist. ESWT was carried out in five sessions with weekly intervals. This procedure can cause bruising, swelling, pain, numbness, or tingling.

PG SI treatments were applied by a single orthopedist. Multiple injections were avoided because they can weaken the plantar fascia and possibly cause ruptures. Plantar fascia at the medial tubercle of the tuberosity of the calcaneus, which can be appreciated with deep palpation of the medial and plantar surface of the calcaneus, was determined by palpation. After local disinfection and anesthesia, a 22-gauge 1.5-inch needle was connected to a $3-\mathrm{cm}^{3}$ syringe filled with $40 \mathrm{mg}$ of methylprednisolone $(1 \mathrm{ml})$ mixed with $0.5 \mathrm{ml}$ of $1 \%$ lidocaine.

Patients had follow ups every 6 weeks for the $1^{\text {st }}$ year. Follow-up visits included mailing questionnaires or interviewing the patient by telephone about updated symptoms and physical examination in the clinic. All the follow-up information was incorporated into a standardized database.

Pain was assessed using a visual analog scale (VAS) score, a modified von Pannewitz score and a 5-level

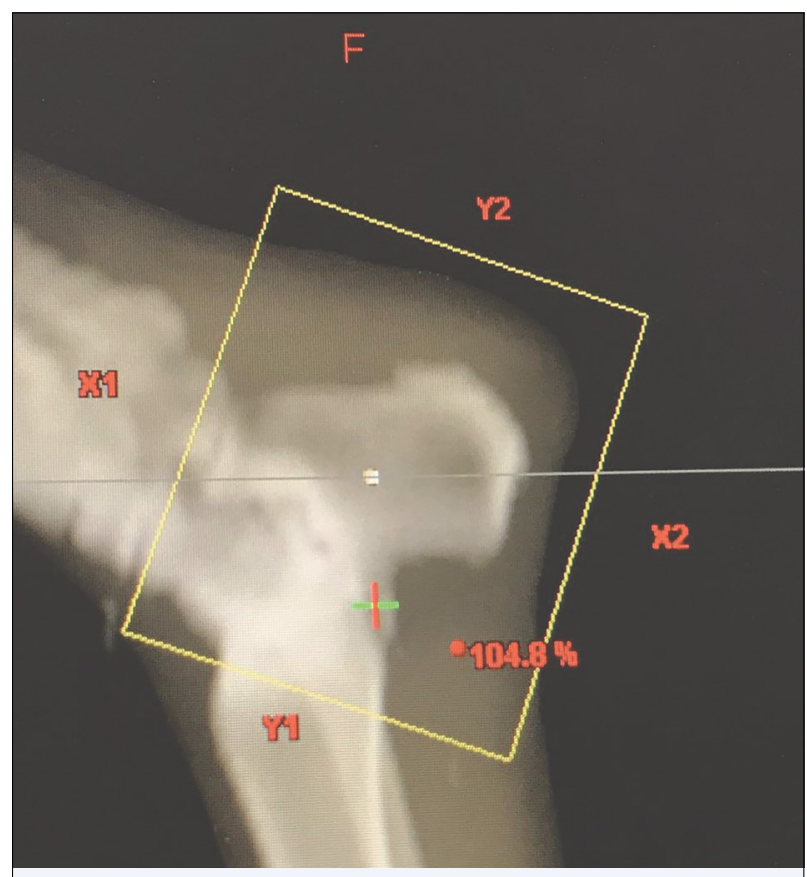

Fig. 1. Lateral radiograpf of treatment field.

function score. The VAS consists of a straight line with the endpoints defining extreme limits from no pain at all (0) to worst possible pain (10). A modified von Pannewitz pain score has five response categories (where complete response $[\mathrm{CR}]=$ pain free, score 1; partial response $[\mathrm{PR}]=$ substantial pain improvement, score 2; minor response $[\mathrm{MR}]=$ pain improvement, score 3; and no change $=$ pain unchanged, score 4 ; or progressive disease $=$ increased or worsening pain, score 5). In a 5-level function score, 90-100 points=excellent; 70-89 points=good; $40-69$ points=fair, and $0-39$ points=poor were determined. All events were evaluated during the 1-year follow-up. Recurrence of symptoms was defined as a painful event requiring second treatment.

\section{Statistical Analysis}

Descriptive statistical methods (mean, standard deviation, and frequency) were used to evaluate the data. The compatibility of the variables with normal distribution was examined by visual (histogram and probability graphs) and analytical methods (KolmogorovSmirnov/Shapiro-Wilk tests). After examining the distribution of variables, the parametric-interval data were analyzed using the student-t-test, paired-t-test, and analysis of variance or variance analysis in recurrent measurements. Non-parametric-interval data were analyzed using Mann-Whitney U-test, Wilcoxon test, Kruskal-Wallis test, or Friedman test. Pairwise 
comparisons were performed using the Mann-Whitney U-test, and the Wilcoxon test and evaluated using the Bonferroni correction. Statistical analyses were run using SPSS version 13 software for Windows.

Univariate and multivariate proportional subdistribution hazard models were used to assess factors associated with the requirement for secondary treatment. The variables which were considered important in the previous studies, including age at treatment, sex, body mass index (BMI) $(25,25-29.9,30-39.9$, and $40<)$, duration of pain ( $\leq 6$ vs. $6<$ ), and treatment scheme (RT, PG-SI, and ESWT), were evaluated. Variables that were significant in the univariate analyses were entered into the multivariate analysis. All P-values resulting from two-sided statistical tests, with values of $\mathrm{p}<0.05$ were considered statistically significant.

Event-free probabilities were estimated and graphically represented as time-to-event curves by means of the Kaplan-Meier method. The Kaplan-Meier method attempts to estimate event-free probabilities and graphically represent time-to-event curves.

\section{Results}

\section{Comparison of Patient Data}

Patient and treatment characteristics are detailed in Table 1. Of the 205 patients participating in the survey 67 (32.7\%) were treated with RT (RT arm), 65 (31.7\%) were treated with PG SI (PG SI arm), and 73 (35.6\%) were treated with ESWT (ESWT arm). Follow-up data were available for patients with a median of 15.5 (range, 6.5-37.4) months. The median follow-up duration for the RT arm was 14.1 (range, 6.5-36) months, and for the ESWT arm was 19.9 (6.5-37.4), whereas for the PG SI arm, it was 12.0 (range, 6.5-18.6) months.

The three treatment groups were comparable with respect to gender, BMI, smoking status, history of chronic pain, impact of pain suffered on quality of life, and leisure/sports. However, the mean duration of pretreatment pain was significantly prolonged for those who treated with the RT arm compared to the PG SI and ESWT arms. There was a statistically significant difference between the treatment groups $(\mathrm{p}=0.016)$. In the subgroup analysis of pain periods, there was a statistically significant difference $(\mathrm{p}=0.006)$ between RT and PG SI. There was no difference between PG SI and ESWT $(\mathrm{p}=0.745)$ and between RT and ESWT $(\mathrm{p}=0.026)$. Among the performance of simple tests, the most significant tests were walking and standing on the heel, were significantly predictive of diagnosis $(\mathrm{p}<0.0001)$ (Table 1).
When the VAS scores before radiation therapy were evaluated, there was a statistically significant difference ( $p=0.004$ ) between the treatment groups. The pretreatment VAS score was 7.7 in the RT arm, 6.9 in the PG SI arm, and 7.5 in the ESWT arm, showing a moderately better pain situation among the patients in the PG SI arm a slightly worse initial pain situation among the patients in the RT arm. In the subgroup analysis of VAS scores, no difference was determined between RT and ESWT $(p=0.347)$. There was a statistically significant difference between PG SI and ESWT $(\mathrm{p}=0.009)$ and between PG SI arm and RT arm ( $\mathrm{p}=0.002)$ (Table 2).

After 3 months, there was a statistically significant difference $(p<0.001)$ between the treatment groups when VAS scores were evaluated. The mean VAS score at time of follow-up after 3 months was 2.5 in the RT arm, 4.6 in the PG SI arm, and 4.1 in the ESWT arm. In the subgroup analysis of VAS scores, no difference was determined between PG SI and ESWT ( $p=0.273$ ). There was a statistically significant difference between RT and ESWT $(\mathrm{p}<0.001)$ and between RT and PG SI $(p<0.001)$. The pain relief results were superior after RT. A similar result was found when evaluating 5-level function: The mean score was 80.4 in the RT arm, 60.2 in the PG SI arm, and 65.6 in the ESWT arm ( $<<0.001)$. In terms of all scores after 3 months, there were a significantly better effects in the RT arm (Table 2).

Comparing the results at the 6 months follow-up with those after 3 months, we found that patients sustained results after 6 months remained stable or even improved. Thus, we can assume that RT provided significant pain reduction compared with other modalities during further follow-up after 3 months (Table 2). In general, the absolute maximum benefit according to the VAS scales was achieved after 3 and 6 months with respect to VAS scores and 5-level function scores in the RT arm $(\mathrm{p}<0.001)$.

Pain control (free of pain, considerable, and some improvement) was achieved by $80.6 \%$ of patients in the RT arm, $72.3 \%$ in the PG SI arm, and 63\% in the ESWT arm. Overall 58 (28.3\%) were event (second treatment requirement) during the follow-up period. Univariate and multivariate analyses for factors associated with events are shown in Table 3. In univariate and multivariate analyses, only treatment scheme was considered as a significant prognostic factor $(\mathrm{p}=0.006)$. Age at treatment, sex, BMI $(25,25-29.9,30-39.9$, and $40<)$, and duration of pain $(\leq 6$ vs. $6<$ ) were not associated with events (all $\mathrm{p}>0.05$ ).

Another prognostic factor for treatment failure was the response after the first treatment. Fifty-eight of 205 
Table 1 Comparison of patient data

\begin{tabular}{|c|c|c|c|c|}
\hline Characteristic & $\begin{array}{l}\text { RT } \\
\text { arm }\end{array}$ & $\begin{array}{l}\text { PG SI } \\
\text { arm }\end{array}$ & $\begin{array}{l}\text { ESWT } \\
\text { arm }\end{array}$ & $\mathbf{p}$ \\
\hline No. of patients, n (\%) & $67(32.7)$ & $65(31.7)$ & $73(35.6)$ & \\
\hline \multicolumn{5}{|l|}{ Age (y) } \\
\hline Mean & 52.5 & 54.7 & 50.4 & 0.027 \\
\hline Range & $(40-74)$ & $(40-74)$ & $(26-78)$ & \\
\hline \multicolumn{5}{|l|}{ Gender, n (\%) } \\
\hline Female & $50(74.6)$ & $52(80)$ & $58(79.5)$ & 0.710 \\
\hline Male & $17(25.4)$ & $13(20)$ & $15(20.5)$ & \\
\hline \multicolumn{5}{|l|}{ Body mass index (mo) } \\
\hline Mean & 33.7 & 33.2 & 31.8 & 0.051 \\
\hline Range & $(21.9-48)$ & $(21.3-43.8)$ & $(22.1-44.1)$ & \\
\hline \multicolumn{5}{|l|}{ Occupation, n (\%) } \\
\hline Standing & $62(92.5)$ & $62(95.4)$ & $61(83.6)$ & 0.048 \\
\hline Sitting & $5(7.5)$ & $3(4.6)$ & $12(16.4)$ & \\
\hline \multicolumn{5}{|l|}{ Cigarette smoker, n (\%) } \\
\hline Yes & $7(12.1)$ & $8(12.3)$ & $12(16.9)$ & 0.659 \\
\hline No & $51(87.9)$ & $57(87.7)$ & $59(83.1)$ & \\
\hline \multicolumn{5}{|c|}{ Localization of spur, $\mathrm{n}(\%)$} \\
\hline Plantar & $34(50.7)$ & $42(64.6)$ & $36(49.3)$ & $<0.001$ \\
\hline Dorsal & $25(37.3)$ & $12(18.5)$ & $2(2.7)$ & \\
\hline Achillodynia & - & - & $12(16.4)$ & \\
\hline Calcaneodynia & - & - & $20(27.4)$ & \\
\hline Both & $8(11.9)$ & $11(16.9)$ & $3(4.1)$ & \\
\hline \multicolumn{5}{|l|}{ Duration of pain (mo) } \\
\hline Mean & 20.5 & 13.9 & 16.4 & 0.016 \\
\hline Range & $(4-120)$ & $(6-48)$ & $(1-96)$ & \\
\hline$\leq 6$ months, $\mathrm{n}(\%)$ & $14(21.2)$ & $23(35.4)$ & $21(29.2)$ & \\
\hline$>6$ months, $\mathrm{n}(\%)$ & $53(78.8)$ & $42(64.6)$ & $52(70.8)$ & \\
\hline \multicolumn{5}{|l|}{ Localization of pain, $\mathrm{n}(\%)$} \\
\hline Right & $20(29.9)$ & $22(33.8)$ & $19(26)$ & 0.420 \\
\hline Left & $22(32.8)$ & $22(33.8)$ & $20(27.4)$ & \\
\hline Right=left & $5(7.5)$ & $11(16.9)$ & $11(15.1)$ & \\
\hline Right $>$ left & $12(17.9)$ & $5(7.7)$ & $14(19.2)$ & \\
\hline Right $<$ left & $8(11.9)$ & $5(7.7)$ & $9(12.3)$ & \\
\hline \multicolumn{5}{|l|}{ Extension of pain, $\mathrm{n}(\%)$} \\
\hline None & $23(34.3)$ & $8(12.3)$ & $25(34.2)$ & $<0.001$ \\
\hline Sole of foot & $16(23.9)$ & $21(32.3)$ & $32(43.8)$ & \\
\hline Calf & $21(31.3)$ & $26(40)$ & $15(20.5)$ & \\
\hline Sole of foot and calf & $7(10.4)$ & $10(15.4)$ & $1(1.4)$ & \\
\hline \multicolumn{5}{|l|}{$\begin{array}{l}\text { Impact of pain on life } \\
\text { quality, } \mathrm{n}(\%)\end{array}$} \\
\hline No impact & $9(13.4)$ & $11(16.9)$ & $15(20.5)$ & $<0.001$ \\
\hline Leisure & $1(1.5)$ & $6(9.2)$ & $11(15.1)$ & \\
\hline Work & $38(56.7)$ & $24(36.9)$ & $2(2.7)$ & \\
\hline Leisure and work & $19(28.4)$ & $24(36.9)$ & $45(61.6)$ & \\
\hline Effects on daily work, $n$ (\%) & & & 0.134 & \\
\hline Able to work & $42(62.7)$ & $33(50.8)$ & $33(45.2)$ & \\
\hline Unable to work & $24(35.8)$ & $30(46.2)$ & $40(54.8)$ & \\
\hline No occupancy & $1(1.5)$ & $2(3.1)$ & - & \\
\hline \multicolumn{5}{|l|}{ Effects on leisure/ } \\
\hline sports, n (\%) & & & 0.076 & \\
\hline Unlimited & - & $1(1.5)$ & $1(1.4)$ & \\
\hline Limited & $5(7.5)$ & $8(12.3)$ & $4(5.5)$ & \\
\hline Impossible & $1(1.5)$ & $4(6.2)$ & $1(1.4)$ & \\
\hline No sports & $61(91)$ & $52(80)$ & $67(91.8)$ & \\
\hline
\end{tabular}

\begin{tabular}{lccccc} 
Table 1 Cont. & & & & \\
Characteristic & $\begin{array}{c}\text { RT } \\
\text { arm }\end{array}$ & $\begin{array}{c}\text { PG SI } \\
\text { arm }\end{array}$ & $\begin{array}{c}\text { ESWT } \\
\text { arm }\end{array}$ & p \\
\hline Test, $\mathrm{n}(\%)$ & & & & $<0.001$ \\
$\quad$ Standing on toes & $9(14.8)$ & $8(12.5)$ & $6(8.6)$ & \\
$\quad$ Walking on toes & $11(17.7)$ & $10(15.5)$ & $8(10.8)$ & \\
$\quad$ Standing on heel & $14(21.8)$ & $15(23.1)$ & $10(13.8)$ & \\
$\quad$ Walking on heel & $30(45.7)$ & $32(48.9)$ & $49(66.8)$ & \\
VAS & & & & \\
$\quad$ Mean & 7.7 & 6.9 & 7.5 & 0.004 \\
$\quad$ Minimum & 4 & 4 & 4 & \\
$\quad$ Maximum & 10 & 10 & 9 & \\
$\quad$ Median & 8 & 7 & 8 & \\
Five-level function score & & & & \\
$\quad$ Mean & 40.9 & 48.4 & 41.9 & $<0.001$ \\
$\quad$ Minimum & 20 & 30 & 20 & \\
Maximum & 70 & 85 & 80 & \\
$\quad$ Median & 40 & 50 & 45 & \\
\hline
\end{tabular}

RT: Radiation therapy; PG SI: Palpation guided steroid injection; ESWT: Extracorporeal shock wave therapy; VAS; Visual analog scale

(28.3\%) patients with no change after completion of the first treatment required a second treatment. The time interval required for the second treatment ranged from 4 months to 14.1 (mean, 9) months after RT, from 3.1 to 13.9 (mean, 7.8) months after ESWT, and from 2.1 to months (mean, 6.4) months after PG SI. The time interval for the second treatment was significantly longer in the RT arm than in the PG SI ( $\mathrm{p}=0.04)$. There was no statistically significant difference among three arms ( $\mathrm{p}=0.069)$.

We also reviewed the distribution of side effects stratified by the treatment modalities. In the PG SI arm acute infection was observed at the injection site in one patient. The patient was treated with antibiotic therapy. In the RT arm no acute side effects were detected. In the ESWT arm pain during treatment occurred in ten patients. In two patients in the ESWT arm, reddening of the skin was present. The patient was treated with anti-inflammatory agents.

\section{Discussion}

The results of this trial of the anlagesic effects of RT, PG SI, and ESWT indicate promising improved pain reduction and quality of life in patients suffering from PF.

Approximately $15 \%$ of all foot complaints admitted to health-care professionals can be attributed to PF.[22] Initial treatment options may include padding and strapping of the foot, therapeutic orthoses, and antiinflammatory medication to manage pain for 6 weeks. 
Table 2 Comparison of patient data after 3 and 6 months

\begin{tabular}{|c|c|c|c|c|c|c|c|c|c|}
\hline Measurement & Value & $\begin{array}{c}\text { RT } \\
\text { arm for } \\
3 \text { months }\end{array}$ & $\begin{array}{c}\text { PG SI } \\
\text { arm for } \\
3 \text { months }\end{array}$ & $\begin{array}{c}\text { ESWT } \\
\text { arm for } \\
3 \text { months }\end{array}$ & $\mathbf{p}$ & $\begin{array}{c}\text { RT } \\
\text { arm for } \\
6 \text { months }\end{array}$ & $\begin{array}{c}\text { PG SI } \\
\text { arm for } \\
6 \text { months }\end{array}$ & $\begin{array}{c}\text { ESWT } \\
\text { arm for } \\
6 \text { months }\end{array}$ & $\mathbf{p}$ \\
\hline \multirow[t]{4}{*}{ VAS } & Mean & 2.5 & 4.6 & 4.1 & $<0.001$ & 2.5 & 4.6 & 3.6 & $<0.001$ \\
\hline & Minimum & 0 & 0 & 0 & & 0 & 0 & 0 & \\
\hline & Maximum & 9 & 10 & 9 & & 10 & 10 & 10 & \\
\hline & Median & 2 & 5 & 4 & & 2 & 5 & 3 & \\
\hline \multirow{4}{*}{$\begin{array}{l}\text { Five-level function } \\
\text { score }\end{array}$} & Mean & 80.4 & 60.2 & 65.6 & $<0.001$ & 80.3 & 59.2 & 68.6 & $<0.001$ \\
\hline & Minimum & 30 & 6 & 30 & & 35 & 0 & 30 & \\
\hline & Maximum & 100 & 100 & 100 & & 100 & 100 & 100 & \\
\hline & Median & 85 & 60 & 65 & & 85 & 60 & 65 & \\
\hline \multirow[t]{4}{*}{ Rowe score, n (\%) } & Excellent & $31(46.3)$ & $10(15.4)$ & $14(19.2)$ & $<0.001$ & $28(43.1)$ & $10(15.4)$ & $17(23.3)$ & $<0.001$ \\
\hline & Good & $24(35.8)$ & $13(20)$ & $6(8.2)$ & & $23(35.4)$ & $15(23.1)$ & $9(12.3)$ & \\
\hline & Moderate & $12(17.9)$ & $32(49.2)$ & $49(67.1)$ & & $13(20)$ & $29(44.6)$ & $44(60.3)$ & \\
\hline & Poor & - & $10(15.4)$ & $4(5.5)$ & & $1(1.5)$ & $11(16.9)$ & $3(4.1)$ & \\
\hline \multirow{6}{*}{$\begin{array}{l}\text { Modified von } \\
\text { Pannewitz pain } \\
\text { score, n (\%) }\end{array}$} & Complete & $28(41.8)$ & $10(15.4)$ & $11(15.1)$ & $<0.001$ & $26(40)$ & $10(15.4)$ & $16(21.9)$ & $<0.001$ \\
\hline & response & & & & & & & & \\
\hline & Partial response & $20(29.9)$ & $7(10.8)$ & $20(27.4)$ & & $21(32.3)$ & $9(13.8)$ & $23(31.5)$ & \\
\hline & Minor response & $10(14.9)$ & $22(33.8)$ & $27(37)$ & & $11(16.9)$ & $20(30.8)$ & $20(27.4)$ & \\
\hline & No change & $8(11.9)$ & $20(30.8)$ & $15(20.5)$ & & $6(9.2)$ & $20(30.8)$ & $14(19.2)$ & \\
\hline & Increased pain & $1(1.5)$ & $6(9.2)$ & - & & $1(1.5)$ & $6(9.2)$ & - & \\
\hline
\end{tabular}

RT: Radiation therapy; PG SI: Palpation guided steroid injection; ESWT: Extracorporeal shock wave therapy; VAS; Visual analog scale

If relief is inadequate, further invasive procedures are required.[23,24]

ESWT has been used in PF for pain relief as an alternative to surgery that allows fast recovery without the potential complications of surgery and the necessity for immobilization. ESWT is used to promote neovascularization to aid in healing degenerative tissue, reduction of calcification, and inhibition of pain receptors found in PF.[25] Although there is no consensus about the most successful treatment method, ESWT is accepted as an effective and safe method in the treatment of chronic PF resistant to conservative treatment. It is recommended for patients who have heel pain for more than 3 months and who do not respond to conservative treatment.[23] Gerdesmeyer et al.[26] demonstrated that ESWT is significantly effective for pain, function, and quality of life compared with a placebo in patients with recalcitrant PF. ESWT proved superior to placebo with regard to changes in VAS composite score of heel pain and overall success rates at 12 weeks, which persist at the 12 months follow-up. In our study, the mean VAS scores had significantly improved 12 months after ESWT $(\mathrm{p}<0.001)$.

In patients with PF, there was a significant heel pain reduction 1 month after using the PG SI method. $[27,28]$ The present study showed similar results re- garding shorter-term pain relief. There was greater pain reduction at 1 month in the PG SI arm and the duration until the second treatment was shortest in the PG SI arm $(\mathrm{p}=0.04)$.

Patients suffering from a wide variety of benign conditions, including PF, have been successfully treated with RT, although it is only used for patients for whom standard treatments are ineffective. In spite of having been known for good results in heel spurs and other inflammatory/degenerative joint disorders in the past, RT has been considered a last resort to treat refractory cases. [29] The total radiation dose given for benign disease is much less than that given in malignancies. The clinical utility and safety of a total dose of $6 \mathrm{~Gy}$ (single fraction of 1 Gy twice a week) were well validated by convincing results in prospective trials. [3032] Accordingly a total dose of 6.0 Gy was applied in 6 fractions of 1.0 Gy 3 times weekly.

In a study by Ott et al.[33] reported complete pain relief was seen in $46 \%$ of patients, partial pain relief in $50 \%$, and unchanged pain in $4 \%$. Similar results were seen in a multicenter cohort study conducted by Micke et al.,[34] in which complete pain relief was reported in $53.2 \%$ of patients and partial pain relief in $30.9 \%$, while $15.9 \%$ of patients reported unchanged pain levels. In the present study, $34.3 \%$ of patients in the RT arm had 
Table 3 Univariate and multivariate analyses of prognostic factors

\begin{tabular}{|c|c|c|c|c|c|c|}
\hline \multicolumn{4}{|c|}{ Univariate analyses } & \multicolumn{3}{|c|}{ Multivariate analyses } \\
\hline Variable & No. & $\begin{array}{l}\text { Event-free probability } \\
\text { (follow-up, months) (\%) }\end{array}$ & $\mathbf{p}$ & Variable & $\begin{array}{l}\text { Hazard Ratio } \\
\qquad(95 \% \mathrm{Cl})\end{array}$ & $\mathbf{p}$ \\
\hline \multirow[t]{2}{*}{ Age (year) } & & & 0.310 & Age (year) & & 0.316 \\
\hline & & & & $\leq 50$ versus $50<$ & $0.76(0.45-1.3)$ & \\
\hline$\leq 50$ & 84 & $33.1(37)$ & & & & \\
\hline $50<$ & 120 & $51.2(37.4)$ & & & & \\
\hline \multirow[t]{2}{*}{ Sex } & & 0.442 & & Sex & & 0.557 \\
\hline & & & & Male versus Female & $1.26(0.59-2.7)$ & \\
\hline Male & 45 & $50.3(37.4)$ & & & & \\
\hline Female & 160 & $42.2(37.4)$ & & & & \\
\hline \multirow[t]{4}{*}{ BMI } & & 0.925 & & BMI & & 0.945 \\
\hline & & & & $<25$ versus $25-29.9$ & $0.65(0.14-3.01)$ & 0.577 \\
\hline & & & & $<25$ versus $30-39.9$ & $0.74(0.17-3.34)$ & 0.698 \\
\hline & & & & $<25$ versus $40<$ & $0.78(0.13-4.47)$ & 0.776 \\
\hline$<25$ & 7 & $64.3(34.8)$ & & & & \\
\hline $25-29.9$ & 46 & $47.6(35.7)$ & & & & \\
\hline $30-39.9$ & 136 & $41.7(37.4)$ & & & & \\
\hline $40<$ & 16 & $48.5(37)$ & & & & \\
\hline \multirow[t]{2}{*}{ Duration of pain (mo) } & & & 0.922 & Duration of pain (mo) & & 0.798 \\
\hline & & & & $\leq 6$ versus $6<$ & $0.93(0.51-1.67)$ & \\
\hline$\leq 6$ & 58 & $48.2(37.4)$ & & & & \\
\hline $6<$ & 145 & $36.9(37.4)$ & & & & \\
\hline Treatment scheme & & & 0.006 & Treatment scheme & & 0.011 \\
\hline \multirow[t]{2}{*}{ RT } & 67 & $59(37)$ & & PG SI versus RT & $0.41(0.2-0.86)$ & 0.018 \\
\hline & & & & PG SI versus ESWT & $0.39(0.2-0.76)$ & 0.005 \\
\hline PG SI & 65 & $33.3(18.6)$ & & & & \\
\hline ESWT & 73 & $47.3(37.4)$ & & & & \\
\hline
\end{tabular}

CI: Confidence interval; BMI: Body mass index; RT: Radiation therapy; PG SI: Palpation guide steroid injection; ESWT: Extracorporeal shock wave therapy

CRs, $31.3 \%$ had PRs, $19.4 \%$ had MRs, and $11.9 \%$ were unchanged at 12 months.

Several retrospective studies have shown that RT for painful heel spurs can have a good analgesic effect. Seegenschmiedt et al.[35] compared three schedules of radiation therapy and found complete pain relief in $67-72 \%$ of the 141 patients. Muecke et al.[36] looked for prognostic factors for pain relief in a multicenter trial. They found that significant prognostic factors for pain relief were age $>58$ years, the use of megavoltage techniques, and the number of therapy series required. In the current study, response rates for RT, PG SI, and ESWT groups were $67.4 \%, 66.6 \%$, and $65.2 \%$. Type of treatment was the only parameter associated with pain relief in univariate and multivariate analyses. Age, sex, BMI, and duration of pain ( $\leq 6$ vs. $6<$ ) were not significant prognostic factors for pain relief.

Despite perceptions that treating a benign disease with $L D$ radiation can induce malignancy, no radiation related secondary malignancies were detected during the nearly 31 years reported follow-up.[37] This concern regarding malignancy from radiation accounts to some extent fort the current limited use of RT for treating benign diseases. The risk of developing radiationinduced secondary malignancies is low in treatment for benign conditions in peripheral tissues due to the reduced chance of scatter radiation to critical organs. $\mathrm{RT}$ is fairly simple to administer at these doses, does not have many symptomatic side effects and frequently leads to good long-term control and improved quality of life.[38] In general, benign conditions require lower doses than treat malignancies; however, use of RT for young patients with these conditions should be considered cautiously.

Pain experienced during all treatment modalities was assessed retrospectively, and hence is a limitation of this study. This retrospective setting is problematic because of the risk of bias comparing three different 
data sets taken from three different centers. A randomized study would be more informative. One of the strengths of the present study is the high number of patients with adequate follow-up (including pain and daily life status), which made a comparison between the more abbreviated and more protracted regimens possible. Furthermore, to the best of our knowledge, this is the first study which compares ESWT with RT when treating PF.

\section{Conclusion}

As a result of our study, RT seems to be the most effective method for moderating pain and improving daily functions in cases of chronic, persistent PF had persisted. ESWT is a safe, effective method in the 12-months follow-up period. PG SI and ESWT were targeted to the painful area but instead RT had the same broad field for everyone. Perhaps treatment to the larger area is the answer and what benefitted RT, and PG SI or ESWT needs administered to be to a larger region and this is what benefited RT.

Peer-review: Externally peer-reviewed.

Conflict of Interest: All authors declared no conflict of interest.

Ethics Committee Approval: The study was approved by the Karadeniz Technical University Faculty of Medicine Scientific Research Ethics Committee (No: 110, Date: 11/10/2019).

Financial Support: None declared.

Authorship contributions: Concept - Ö.A., A.Y.Z., E.C.; Design - Ö.A., A.Y.Z., E.C.; Supervision - Ö.A., E.C.; Funding - Ö.A., E.C.; Materials - Ö.A., E.C.; Data collection and/ or processing - Ö.A., E.C., F.C., O.A., F.Z.; Data analysis and/or interpretation - Ö.A., E.C., L.S., E.H.,A.Y.; Literature search - Ö.A., E.C., A.Y.; Writing - Ö.A.; Critical review Ö.A., E.C.

\section{References}

1. Tahririan MA, Motififard M, Tahmasebi MN, Siavashi B. Plantar fasciitis. J Res Med Sci 2012;17(8):799-804.

2. Cheung JT, Zhang M, An KN. Effect of aschilles tendon loading on plantar fascia tension in the standing foot. Clin Biomech 2006;21(2):194-203.

3. Young C. In the clinic. Plantar fasciitis. Ann Intern Med 2012;156(1):1-15.

4. Thomas JL, Christensen JC, Kravitz SR, Mendicino RW, Schuberth JM, Vanore JV, et al. The diagnosis and treatment of heel pain: A clinical practice guidelinerevision 2010. J Foot Ankle Surg 2010;49(3):1-19.

5. Akfirat M, Sen C, Gunes T. Ultrasonographic appearance of the plantar fasciitis. Clin Imaging 2003;27(5):353-57.

6. Dasgupta B, Bowles J. Sintigraphic localisation of steroid injection site in plantar fasciitis. Lancet 1995;346(8987):1400-1.

7. Evans A. Podiatric medical applications of posterior night stretch splinting. J Am Podiatr Med Assoc 2001;91(7):356-60.

8. Hammer DS, Adam F, Kreutz A, Rupp S, Kohn D, Seil R. Ultrasonographic evaluation at 6-month followup of plantar fasciitis after extracorporeal shock wave therapy. Arch Orthop Trauma Surg 2005;125(1):6-9.

9. Osborne HR, Allison GT. Treatment of plantar fasciitis by Low Dye taping and iontophoresis: Short term results of a double blinded, randomised, placebo controlled clinical trial of dexamethasone and acetic acid. Br J Sports Med 2006;40(6):545-49.

10. Tounton JE, Ryan BE, Clement DB, Mckenzie DC, Lioyd-Smith DR. Plantar fasciitis: A retrospective analysis of 267 cases. Phys Ther Sport 2002;3(2):57-65.

11. Othman AM, Ragab EM. Endoscopic plantar fasciotomy versus extracorporeal shock wave therapy for treatment of chronic plantar fasciitis. Arch Orthop Trauma Surg 2010;130(11):1343-7.

12. Hildebrandt G, Maggiorella L, Rodel F, Rödel V, Willis D, Trott KR. Mononuclear cell adhesion and cell adhesion molecule liberation after X-irradiation of activated endothelial cells in vitro. Int J Radiat Biol 2002;78(4):315-25.

13. Hildebrandt G, Seed MP, Freemantle CN, Alam CA, Colville-Nash PR, Trott KR. Mechanisms of the antiinflammatory activity of low-dose radiation therapy. Int J Radiat Biol 1998;74(4):367-78.

14. Scahue D, MArples B, Trott KG. The effect of low dose $\mathrm{X}$ irradiation on the oxidative burst in stimulated macrophages. Int J Radiat Biol 2002;78(7):567-76.

15. Schafer U, Micke O, Seegenschmiedt MH, Mucke R. Correspondence (letter to the editor): Low-dose radiotherapy. Dtsch Arztebl Int 2010;107(34-35):603-4.

16. Turhan Y, Arıcan M, Karaduman ZO. Efficacy of extracorporeal shock wave therapy in the treatment of achilles tendinopathy: Clinical and functional outcomes. Anatol Clin J Med Sci 2019;24(1):22-5.

17. Abdoli A, Roohi BN. Effect of extracorporeal shockwave therapy versus stretching in the treatment of athletes with chronic plantar fasciitis. Phys Treat 2019;9(2):117-23.

18. Rompe JD, Decking J, Schoellner C, Nafe B. Shock wave application for chronic plantar fasciitis in running athletes. A prospective, randomized, placebocontrolled trial. Am J Sports Med 2003;31(2):268-75. 
19. Sems A, Sems A, Dimeff R, Iannotti JP. Extracorporeal shock wave therapy in the treatment of chronic tendinopathies. J Am Acad Orthop Surg 2006;14(4):195-204.

20. Porter MD, Shadbolt B. Intralesional corticosteroid injection versus extracorporeal shock wave therapy for plantar fasciopathy. Clin J Sports Med 2005;15(3):11924.

21. Canyilmaz E, Canyilmaz F, Aynaci O, Colak F, Serdar L, Uslu GH, et al. Prospective comparison of radiation therapy and local steroid injection for the treatment of plantar fasciitis. Int J Radiat Oncol Biol Phys 2015;92(3):659-66.

22. League AC. Current concepts review: Plantar fasciitis. Foot Ankle Int 2008;29(3):358-66.

23. Landorf KB, Radford JA, Keenan AM, Redmond AC. Effectiveness of low-dye taping for the short-term management of plantar fasciitis. J Am Podiatr Med Assoc 2005;95(6):525-30.

24. Glazer JL. An approach to the diagnosis and treatment of plantar fasciitis. Phys Sportsmed 2009;37(2):74-9.

25. Rompe JD, Furia J, Weil L, Maffulli N. Shock wave therapy for chronic plantar fasciopathy. Br Med Bull 2007;81-82(1):183-208.

26. Gerdesmeyer L, Frey C, Vester J, Maier M, Weil L Jr., Weil L Sr., et al. Radial extracorporeal shock wave therapy is safe and effective in the treatment of chronic recalcitrant plantar fasciitis: Results of a confirmatory randomized placebo-controlled multicenter study. Am J Sports Med 2008;36(11):2100-9.

27. Ball EM, McKeeman HM, Patterson C, Burns J, Yau WH, Moore OA, et al. Steroid injection for inferior heel pain: A randomised controlled trial. Ann Rheum Dis 2013;72(6):996-1002.

28. Li S, Shen T, Liang Y, Zhang Y, Bai B. Miniscalpelneedle versus steroid injection for plantar fasciitis: A randomized controlled trial with a 12-month follow-up. Evid Based Complement Alternat Med 2014;2014:164714.

29. Ende CH, Minten MJ, Hoogenboom MM, Hoogen PF, Broeder AA, MAhler EA, et al. Long-term efficacy of low-dose radiation therapy on symptoms in patients with knee and hand osteoarthritis: Follow-up results of two parallel randomised, sham-controlled trials.
Lancet Rheumotol 2020;2(1):42-9.

30. Prokein B, Holtmann H, Hautmann MG, Rösler HP, Graeber S, Dzierma Y, et al. Radiotherapy of painful heel spur with two fractionation regimens: Results of a randomized multicenter trial after 48 weeks' followup. Strahlenther Onkol 2017;93(6):483-90.

31. Heyd R, Tselis N, Ackermann H, Roddiger SJ, Zamboglou N. Radiation therapy for painful heel spurs: Results of a prospective randomized study. Strahlenther Onkol 2007;183(1):3-9.

32. Niewald M, Seegenschmiedt MH, Micke O, Graeber S, Muecke R, Schaefer V, et al. Randomized, multicenter trial on the effect of radiation therapy on plantar fasciitis (painful heel spur) comparing a standard dose with a very low dose: Mature results after 12 months' follow-up. Int J Radiat Oncol Biol Phys 2012;84(4):45562.

33. Ott OJ, Jeremias C, Gaipl US, Frey B, Schmidt M, Fietkau R. Radiotherapy for calcaneodynia. Results of a single center prospective randomized dose optimization trial. Strahlenther Onkol 2013;189(4):329-34.

34. Micke O, Seegenschmiedt MH, German Cooperative Group on Radiotherapy for Benign Diseases. Radiotherapy in painful heel spurs (plantar fasciitis)-results of a national patterns of care study. Int J Radiat Oncol Biol Phys 2004;58(3):828-43.

35. Seegenschmiedt MH, Keilholz L, Katalinic A, Stecken A, Sauer R. Heel spur: Radiation therapy for refractory pain results with three treatment concepts. Radiology 1996;200(1):271-6.

36. Muecke R, Micke O, Reichl B, Heyder R Prott FJ, Seegenschmiedt $\mathrm{MH}$, et al. Demographic, clinical and treatment related predictors for event-free probability following low dose radiotherapy for painful heel spursda retrospective multicenter study of 502 patients. Acta Oncol 2007;46(2):239-46.

37. Surenkok S, Dirican B, Beyzadeoglu M, Oysul K. Heel spur radiotherapy and radiation carcinogenesis risk estimation. Radiat Med 2006;24(8):573-6.

38. McKeown SR, Hatfield P, Prestwich RJ, Shaffer RE, Taylor RE. Radiotherapy for benign disease; assessing the risk of radiation-inducedcancer following exposure to intermediate dose radiation. Br J Radiol 2015;88(1056):20150405. 